Inês R. Violante, $\mathrm{PhD}$ Miguel Patricio, $\mathrm{PhD}$ Inês Bernardino, $\mathrm{PhD}$ José Rebola, PhD Antero J. Abrunhosa, $\mathrm{PhD}$

Nuno Ferreira, $\mathrm{PhD}$ Miguel Castelo-Branco, $\mathrm{MD}, \mathrm{PhD}$

Correspondence to Dr. Violante: i.violante@imperial.ac.uk

Supplemental data at Neurology.org

\section{GABA deficiency in NF1}

\section{A multimodal $\left[{ }^{11} \mathrm{C}\right]$-flumazenil and spectroscopy study OPEN}

\section{ABSTRACT}

Objective: To provide a comprehensive investigation of the $\gamma$-aminobutyric acid (GABA) system in patients with neurofibromatosis type 1 (NF1) that allows understanding the nature of the GABA imbalance in humans at pre- and postsynaptic levels.

Methods: In this cross-sectional study, we employed multimodal imaging and spectroscopy measures to investigate GABA type $A\left(G A B A_{A}\right)$ receptor binding, using $\left[{ }^{11} \mathrm{C}\right]$-flumazenil $P E T$, and $G A B A$ concentration, using magnetic resonance spectroscopy (MRS). Fourteen adult patients with NF1 and 13 matched controls were included in the study. MRS was performed in the occipital cortex and in a frontal region centered in the functionally localized frontal eye fields. PET and MRS acquisitions were performed in the same day.

Results: Patients with NF1 have reduced concentration of GABA + in the occipital cortex ( $p=$ $0.004)$ and frontal eye fields $(p=0.026)$. PET results showed decreased binding of $\mathrm{GABA}_{A}$ receptors in patients in the parieto-occipital cortex, midbrain, and thalamus, which are not explained by decreased gray matter levels.

Conclusions: Abnormalities in the GABA system in NF1 involve both GABA concentration and $G_{A B A}$ receptor density suggestive of neurodevelopmental synaptopathy with both pre- and postsynaptic involvement. Neurology ${ }^{\circledR}$ 2016;87:897-904

\section{GLOSSARY}

BOLD $=$ blood oxygen level-dependent; $\mathbf{B P}=$ binding potential; FEF $=$ frontal eye field; $\mathbf{G A B A}=\gamma$-aminobutyric acid; $\mathbf{G A B A}_{\mathbf{A}}=\gamma$-aminobutyric acid type $\mathrm{A} ; \mathbf{G M}=$ gray matter; $\mathbf{M N I}=$ Montreal Neurological Institute; $\mathbf{M R S}=$ magnetic resonance spectroscopy; NAA $=\mathrm{N}$-acetylaspartate; $\mathbf{N A A G}=\mathrm{N}$-acetylaspartylglutamine; $\mathbf{N F 1}=$ neurofibromatosis type $1 ; \mathbf{R O I}=$ region of interest; $\mathbf{W M}=$ white matter.

Neurofibromatosis type 1 (NF1) is a neurodevelopmental monogenetic disorder, characterized by multisystemic symptoms, including increased incidence of cognitive deficits $(50 \%-70 \%)^{1}$ and predisposition for tumor development. ${ }^{2}$ Cognitive impairments occur even in the absence of visible brain alterations, suggesting the existence of pathophysiologic abnormalities at a finer scale.

One hypothesis to explain the cognitive and behavioral profile is based on neurochemical imbalance in the $\gamma$-aminobutyric acid (GABA) system. Evidence for it includes (1) cellular and molecular studies in the $\mathrm{NfI}^{+/-}$model, which established a connection between RAS regulation by the NF1 gene, GABAergic signaling, and learning deficits ${ }^{3,4}$; and (2) in vivo magnetic resonance spectroscopy (MRS) studies in children with NF1 showing reduced GABA levels.,

Moreover, it is possible that GABAergic alterations influence the distribution or binding affinity of GABA receptors, consistent with the "GABA shift." "This model postulates that increased GABA levels enhance the affinity of GABA type $A\left(G_{A B A}\right)$ receptors for benzodiazepine ligands. The directionality of changes in disease is, however, difficult to predict. On one hand, in homeostatic systems, the natural prediction is that, to maintain efficient

\footnotetext{
From the Institute for Biomedical Imaging and Life Sciences, Faculty of Medicine (I.R.V., M.P., I.B., J.R., M.C.-B.), Laboratory of Biostatistics and Medical Informatics, Faculty of Medicine (M.P., M.C.-B.), and Institute of Nuclear Sciences Applied to Health (A.J.A., N.F., M.C.-B.), University of Coimbra, Portugal; and Division of Brain Sciences (I.R.V.), Department of Medicine, Hammersmith Hospital Campus, Imperial College London, UK.

Go to Neurology.org for full disclosures. Funding information and disclosures deemed relevant by the authors, if any, are provided at the end of the article. The Article Processing Charge was paid by the Wellcome Trust.

This is an open access article distributed under the terms of the Creative Commons Attribution License 4.0 (CC BY), which permits unrestricted use, distribution, and reproduction in any medium, provided the original work is properly cited.
} 
neurotransmission, low GABA levels lead to increasing numbers of GABA receptors. On the other hand, reduced GABA concentration in patients could reflect a compensatory mechanism to counterbalance pre- and postsynaptically the effects of increased GABA release caused by reduced neurofibromin expression. ${ }^{4}$ GABA metabolism can be downregulated as a response to increased GABAergic neurotransmission, thus limiting GABA availability for packaging and release. ${ }^{8}$ If this were the case, we expect observing low GABA levels accompanied by a reduction in the number of GABA receptors. To further characterize the GABA system in adults with NF1, we studied the distribution of $\mathrm{GABA}_{\mathrm{A}}$ receptors using $\left[{ }^{11} \mathrm{C}\right]$-flumazenil PET, and GABA concentration using MRS.

METHODS Participants. We performed a cross-sectional study in 14 adult patients with NF1, diagnosed by the NIH criteria, ${ }^{9}$ and 14 healthy controls, matched for age, sex, and educational level. All participants were right-handed.

Exclusion criteria included psychiatric disorder, neurologic illness affecting brain function other than NF1, IQ $<75$, epilepsy, traumatic brain injury, or a clinically significant intracranial abnormality detected on MRI. T2 hyperintensities (commonly found in NF1) were not considered an exclusion criterion for patients. However, if present within the voxels prescribed for spectroscopy, the correspondent spectrum was not included. Our final cohort comprised 14 patients with NF1 (mean age $34.7 \pm 7.1$ years, 4 males) and 13 matched controls (mean age $36 \pm 8.9$ years, 4 males) (table 1$)$.

None of the participants were taking medication. Three patients reported taking antidepressants in the past (for periods

\section{Table 1 Demographics and neuropsychological testing performance}

$\begin{array}{llll} & \text { NF1 } & \text { Controls } & p \text { Value } \\ \text { Demographics } & & & \\ \text { No. of participants } & 14 & 13 & 0.697 \\ \text { Age, } y, \text { mean } \pm \text { SD } & 34.7 \pm 7.1 & 36 \pm 8.9 & 0.901 \\ \text { Sex, female/male } & 10 / 4 & 9 / 4 & 0.160 \\ \text { Years of education } & 11.4 \pm 4.5 & 13.7 \pm 3.5 & \\ \text { Handedness, R/L } & 14 / 0 & 13 / 0 & \\ \text { Neuropsychological } & & & 0.002^{\mathrm{a}} \\ \text { WAIS-III } & & 116.15 \pm 11.8 & <0.001^{\mathrm{a}} \\ \text { Total IQ } & 99.5 \pm 13.7 & 119.3 \pm 12.2 & 0.030 \\ \text { Performance IQ } & 99.1 \pm 13.5 & 111.3 \pm 12.6 & \\ \text { Verbal IQ } & 100.2 \pm 12.5 & & \end{array}$

Abbreviations: NF1 = neurofibromatosis type 1; WAIS-III = Wechsler Adult Intelligence Scale-III.

Performance data are presented as means \pm SD.

a Significant results after correcting for multiple comparisons using the Holm-Šídák method $(\alpha=0.05)$. ranging between 6 months to 3 years), but none were medicated in the year before the study. One control was medicated with antidepressants and stopped the medication a month before taking part in the study. None of the participants were ever medicated with anticonvulsants. Participants were instructed to withhold from drinking alcohol 24 hours before testing and from smoking or drinking coffee on the day of testing. All participants scored below the cutoff $(<8)$ defined for hazardous and harmful alcohol use in the AUDIT (Alcohol Use Disorders Identification Test). ${ }^{10,11}$ Groups did not significantly differ in their scores (NF1: $2.07 \pm 1.69$; controls: $2.85 \pm 2.54 ; t_{25}=0.939, p=0.36$ ).

Neuropsychological testing. IQ was assessed using the Portuguese version of the Wechsler Adult Intelligence Scale-III. ${ }^{12} \mathrm{~Pa}-$ tients with NF1 had IQ values in the normal range but significantly lower than controls (independent-samples $t$ tests; Total IQ, $p=0.002$; Performance IQ, $p<0.001$; Verbal IQ, $p=0.030)$.

Imaging. Participants underwent all imaging acquisitions in the same day. PET and MRI order was counterbalanced. MRS was performed in the occipital cortex, to investigate whether GABA deficits persist into adulthood, and the frontal eye fields (FEFs). The latter was chosen because of its numerous cortical inhibitory circuits and because its location is easily identified using a functional localizer.

MRI and MRS acquisitions. Scanning was performed using a 3 T Tim Trio (Siemens, Erlangen, Germany) with a 12-channel head coil. Acquisitions were as follows: (1) T1-weighted magnetization-prepared rapid-acquisition gradient echo for voxel placement and volumetric measurements; (2) T2-weighted fluid-attenuated inversion recovery to identify T2 hyperintensities; (3) functional localizer for the FEF using single-shot echo planar imaging. Participants performed an oculomotor task as described in the e-Methods at Neurology.org. Individual brain activation was examined using Neuro3D (Siemens) to allow immediate placement of the MRS voxel. (4) 2xGABA-edited spectra, MEGA-PRESS method. ${ }^{13}$ The occipital voxel was positioned within the occipital cortex with its lower face aligned with the cerebellar tentorium (figure 1A and figure e-1 for position across all participants). The FEF voxel was positioned based on the blood oxygen level-dependent (BOLD) activation elicited by the functional localizer (figure 1B and figure e-1 for position across all participants). In 2 NF1 participants, the voxel was placed according to anatomical landmarks (junction of precentral sulcus and superior frontal sulcus) because of insufficient BOLD activation. All voxels were placed on the right FEF with the exception of 2 participants who showed a lateralization of the FEF activation to the left hemisphere (2 patients with NF1). (5) ${ }^{1} \mathrm{H}$ PRESS in the occipital and FEF positions. Detailed scan measures can be found in the e-Methods.

MRI volumetric analyses. T1-weighted images were segmented using the VBM8 toolbox (http://dbm.neuro.uni-jena.de/ $\mathrm{vbm} /$ ) in SPM8 (http://www.fil.ion.ucl.ac.uk/spm) to determine the relative proportions of gray matter (GM), white matter (WM), and CSF. This was used to determine tissue proportions in the spectroscopic voxels using Matlab7 (The MathWorks Inc., Natick, MA) and to perform voxel-based morphometry (e-Methods). The latter was used to investigate the potential confound that group differences in $\left[{ }^{11} \mathrm{C}\right]$-flumazenil binding could partially arise from counterpart differences in GM volume. ${ }^{14}$

fMRI analyses. Data processing and analysis were performed in BrainVoyager QX2.3 (Brain Innovation, Maastricht, the Netherlands). Preprocessing included slice time correction, linear trend removal, temporal high-pass filtering (3 cycles per run), 
Figure $1 \quad$ Magnetic resonance spectroscopy measurements

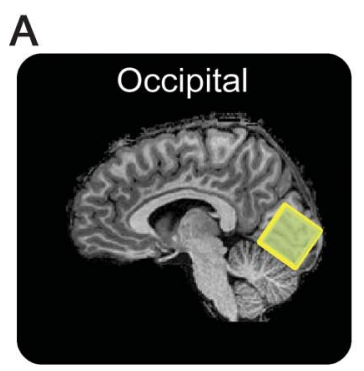

B

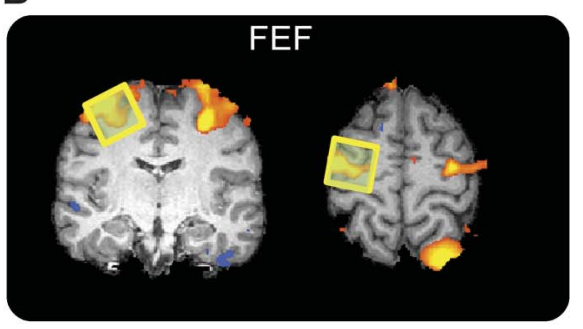

C
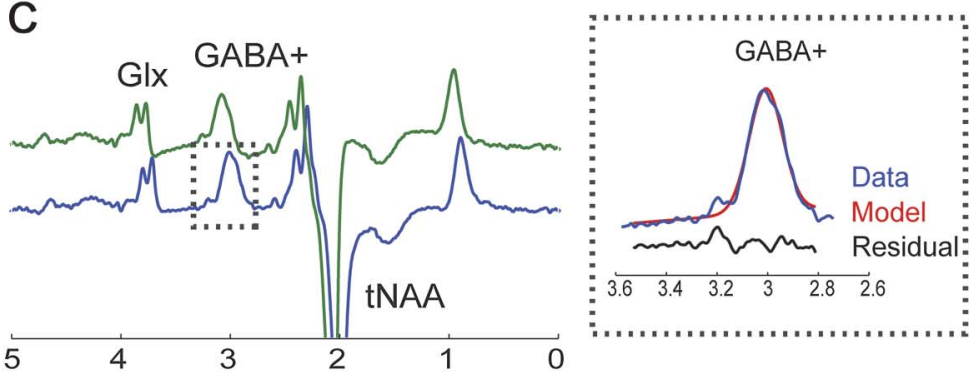

D

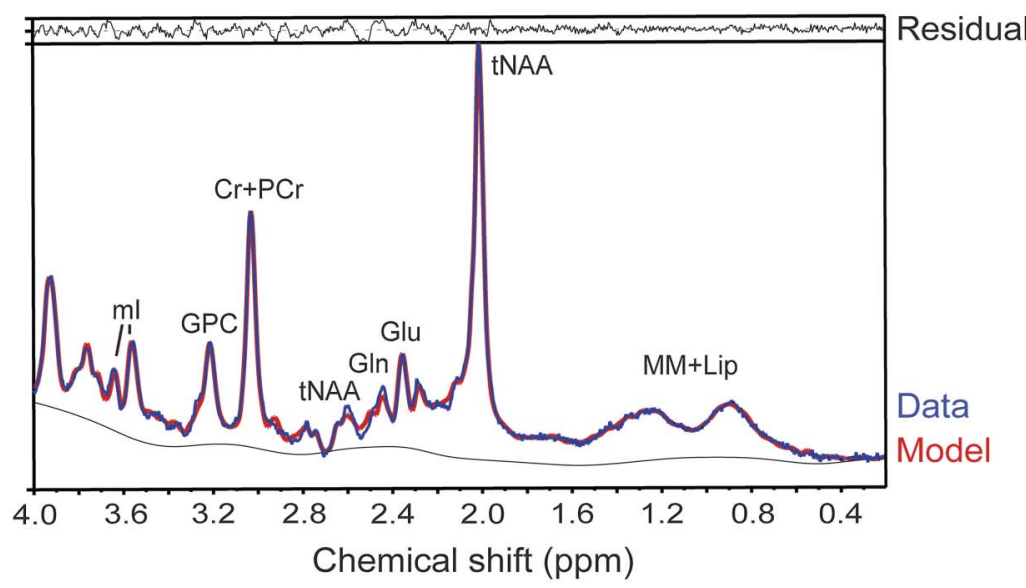

Localization of the magnetic resonance spectroscopy voxel (yellow square) in the visual cortex (A) and FEF as localized with a functional localizer (B). (C) Edited magnetic resonance spectroscopy spectrum from a representative participant showing clearly resolved peaks for GABA + and glutamine + glutamate (GIx). The inset on the right shows the fit output for the GABA + signal. MEGA-PRESS spectra were processed using the Gannet 2.0 toolkit, the green line shows the raw GABA data, the blue line the postphase and frequency aligned GABA data, and the black line is the residual difference between the experimental data and the curve fit. (D) Single-voxel-localized PRESS spectrum (blue line) from a representative participant with spectral fits (red line) and the residual difference between the experimental data and the curve fit (black line) determined using LCModel. $\mathrm{Cr}=$ creatine; FEF = frontal eye field; GABA = $\gamma$-aminobutyric acid; Gln = glutamine; Glu = glutamate; GPC = glycerophosphocholine; $\mathrm{ml}=$ myo-inositol; $\mathrm{PCr}=$ phosphocreatine; $\mathrm{tNAA}=$ total $\mathrm{N}$-acetylaspartate (NAA [N-acetylaspartate] + NAAG [N-acetylaspartylglutamine]).

motion correction, and spatial smoothing (full width at half maximum 5-mm gaussian kernel). No participant had within-run movements $>3 \mathrm{~mm}$. Predictors for the general linear model were built by convolving a boxcar time course with a 2 -gamma function. BOLD signal peak amplitude (\% signal change) for the proand antisaccade contrasts, at the peak voxel, were extracted for each participant in the FEF and occipital regions.

MRS analyses. MEGA-PRESS. The signal detected at 3.02 ppm is known to contain contributions from both macromolecules and homocarnosine, ${ }^{15}$ and is therefore referred to as
$\mathrm{GABA}+$. Quantification of GABA+ (figure 1B) was performed using the Gannet 2.0 toolkit ${ }^{16}$ to yield a $\mathrm{GABA}+/ \mathrm{H}_{2} \mathrm{O}$ ratio (institutional units). Only spectra with relative fit error $<15 \%$ were included. Based on this criterion, the FEF spectra from 2 controls and $4 \mathrm{NF} 1 \mathrm{~s}$ were excluded. For one control, the FEF spectrum was not acquired because of technical difficulties. Therefore, we included data from the FEFs of 10 controls and 9 patients. For the occipital voxel, we included data from 12 controls and 14 patients as one control was identified as an outlier (upper fence/hinge) and excluded from the analysis.

To account for differences in voxel tissue composition, the voxel fraction of WM $\left(f_{\mathrm{WM}}\right)$ and $\mathrm{GM}\left(\mathrm{f}_{\mathrm{GM}}\right)$ was used to normalize the GABA+ concentration according to: $\mathrm{GABA}+{ }_{\text {corr }}=$ $\mathrm{GABA}+/\left(\mathrm{f}_{\mathrm{WM}}+\mathrm{f}_{\mathrm{GM}}\right)$.

PRESS. LCModel software (version 6.3) was used for metabolite quantification applying the internal water reference method, accounting for different water content in GM, WM, and CSF. ${ }^{17}$ Only metabolites with Cramér-Rao bounds $<20 \%$ were considered. Concentrations of $N$-acetylaspartate (NAA) plus $N$-acetylaspartylglutamine (NAAG), creatine plus phosphocreatine, glycerophosphocholine, myo-inositol, glutamate, and glutamine were included for analysis. Concentrations in millimole units were calculated for all metabolites and results are presented in institutional units.

$\left[{ }^{11}\right.$ C]-Flumazenil PET. A Philips Gemini GXL scanner (Philips Medical Systems, Best, the Netherlands) was used to acquire a CT scan and 26 sequential 3-dimensional PET frames of the entire brain (90 slices, 2-mm slice sampling), over a period of 60 minutes, after the bolus injection of $584.6 \pm 25.9$ $\mathrm{MBq}\left[{ }^{11} \mathrm{C}\right]$-flumazenil. PET data were reconstructed using a LOR-RAMLA algorithm. Voxel-by-voxel binding potential (BP) was calculated from dynamic PET images using the basis function implementation of the Simplified Reference Tissue Model, with the pons as reference. ${ }^{18,19}$ Several studies showed that using the pons activity as a reference is reliable and highly correlated with the BP values estimated by the arterial sampling method. ${ }^{20}$ Moreover, to ensure that systematic differences in the pons time-activity curves did not affect the results, we compared standard uptake values in the pons between the 2 groups (independent-samples, $t_{25}=0.370, p=0.714$ ).

PET data were normalized to Montreal Neurological Institute (MNI) space after rigidly coregistering the individual PET scan to the participant anatomical T1 scan in SPM8. The latter were segmented using the unified segmentation method ${ }^{21}$ in order to extract the transformation map into MNI space. This was then used to nonlinearly warp the PET scans. The resulting normalized images were smoothed using an isotropic gaussian kernel (12 $\mathrm{mm}$ full width at half maximum).

We performed exploratory whole-brain and region-of-interest (ROI)-based analyses. Whole-brain group differences were evaluated in SPM8 using independent-samples $t$ test. $\left[{ }^{11} \mathrm{C}\right]$-Flumazenil BP differences were considered statistically significant at peak height threshold of uncorrected $p<0.005$ with cluster size greater than 230 contiguous voxels, which corresponds to a threshold of $p<0.05$ corrected by cluster level for multiple comparisons as estimated by 10,000 Monte Carlo simulations in 3dClustSim (AFNI, http://afni.nimh.nih.gov/afni/). ROI-based analyses were performed in regions used for spectroscopy. The mean $\mathrm{BP}$ at these voxels was determined with the objective of investigating the relation between GABA concentration and $\mathrm{GABA}_{\mathrm{A}} \mathrm{BP}$.

Statistical analyses. Data were transferred to SPSS version 21 (IBM Corp., Armonk, NY) for analysis. All dependent variables were tested for normality of distribution using the Shapiro-Wilk 
test and for outliers using the Tukey method. All variables were normally distributed.

Group differences were evaluated using independent-samples $t$ tests and corrected for multiple comparisons using the Holm-Šídák method $(\alpha=0.05)$. ROI analyses were performed using independent-samples $t$ test and Pearson correlations (robustness estimated using bootstrapping, 10,000 iterations, to provide $95 \%$ confidence intervals). Effect sizes were calculated using Cohen $d$. Variance was similar between the groups as tested using the Levene test of homogeneity of variances.

Standard protocol approvals, registrations, and patient consents. Study procedures were reviewed and approved by the Ethics Commission of the Faculty of Medicine of the University of Coimbra. Participants provided written informed consent.

RESULTS MRS results. Patients with NF1 displayed decreased GABA + levels, of on average $11.5 \%$, in the occipital cortex $\left(t_{24}=3.172, p=0.004, d=\right.$ $1.14)$ and $22 \%$ in the FEF $\left(t_{17}=2.443, p=0.026\right.$, $d=1.27$ ) (figure 2). In addition, patients showed lower levels of NAA + NAAG $\left(t_{25}=3.361, p=\right.$ 0.002 , $d=1.31 ; 12 \%$ reduction) and glutamate $\left(t_{25}=2.787, p=0.01, d=1.08 ; 10 \%\right.$ reduction $)$ in the occipital cortex (figure 2). A full summary of the spectroscopy results can be found in table e-1.

PET results. Whole-brain voxel-based analyses indicated that patients with $\mathrm{NF} 1$ have decreased $\left[{ }^{11} \mathrm{C}\right]$-flumazenil $\mathrm{BP}$ in a left parieto-occipital region that encompasses

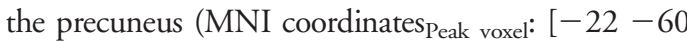
$30]$; $z$ score $=3.65, \mathrm{k}=381, p<0.05$ corrected, $d=1.89)$ and in a region that includes the left midbrain and thalamus (MNI coordinates Peak voxel: $[-2-34-10] ; z$ score $=2.95, \mathrm{k}=447, p<0.05$ corrected, $d=1.64$ ), whereas no brain regions displayed increased BP in patients (figure 3). Moreover, VBM showed that decreased $\left[{ }^{11} \mathrm{C}\right]-$ flumazenil BP in patients is not explained by decreased GM content, as decreased GM and decreased $\mathrm{BP}$ in patients do not colocalize (figure e-2). Moreover, to ensure that PET results were not hindered by concomitant abnormalities in GM, we performed correlation analyses between GM density and BP in the regions showing decreased PET BP. No correlation was observed for patients or controls (e-Methods), confirming that decreased BP in patients is not explained by GM alterations.

ROI-based analysis for the occipital and FEF voxels showed no statistically significant group differences in BP (occipital: $t_{25}=0.519, p=$ $0.608, d=0.20$; FEF: $t_{24}=0.936, p=0.359$, $d=0.37$ )

Cross-modality correlations. The relationship between the density of $\mathrm{GABA}_{\mathrm{A}}$ receptors and the concentration of GABA was examined in occipital and FEF voxels. In patients, the concentration of GABA+ was negatively correlated with the density of $\mathrm{GABA}_{\mathrm{A}}$ receptors in the FEF $(r=-0.842, p=0.004, \mathrm{n}=9$, $95 \%$ confidence interval $=-1.000$ to -0.368 ) but

Figure 2 Magnetic resonance spectroscopy alterations in patients with NF1
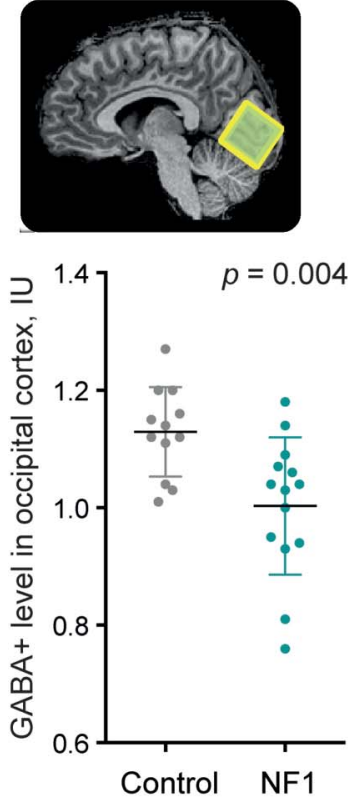

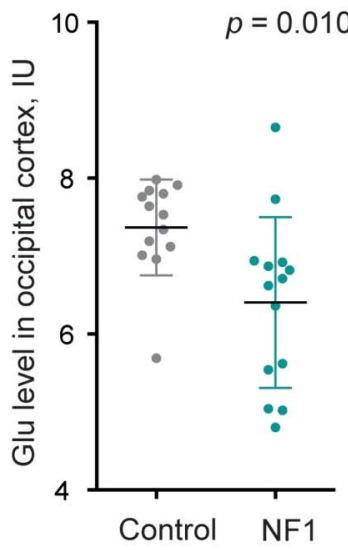

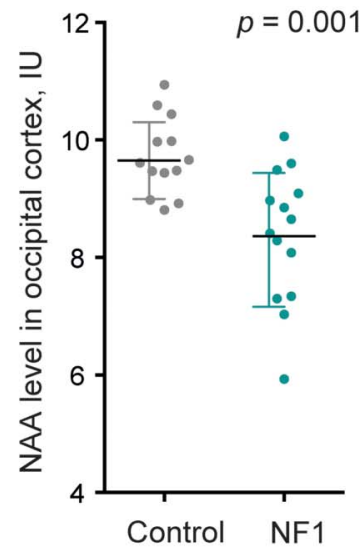

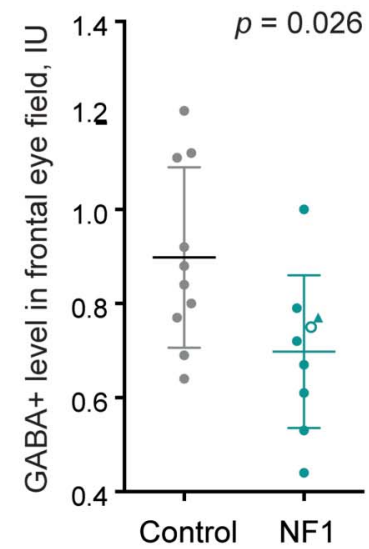

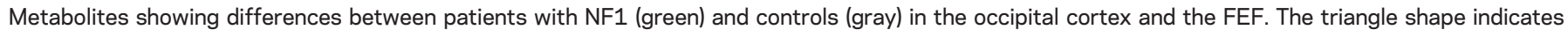

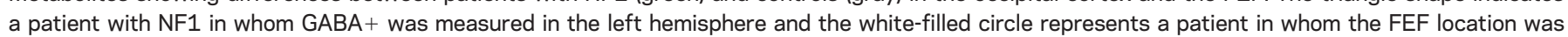

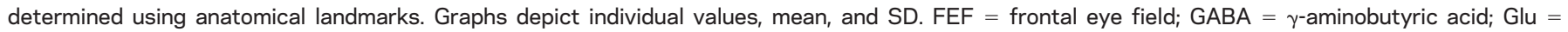
glutamate; NAA = N-acetylaspartate; NF1 = neurofibromatosis type 1 . 
Figure $3 \quad\left[{ }^{11} \mathrm{C}\right]-$ Flumazenil PET binding differences between patients with NF1 and controls

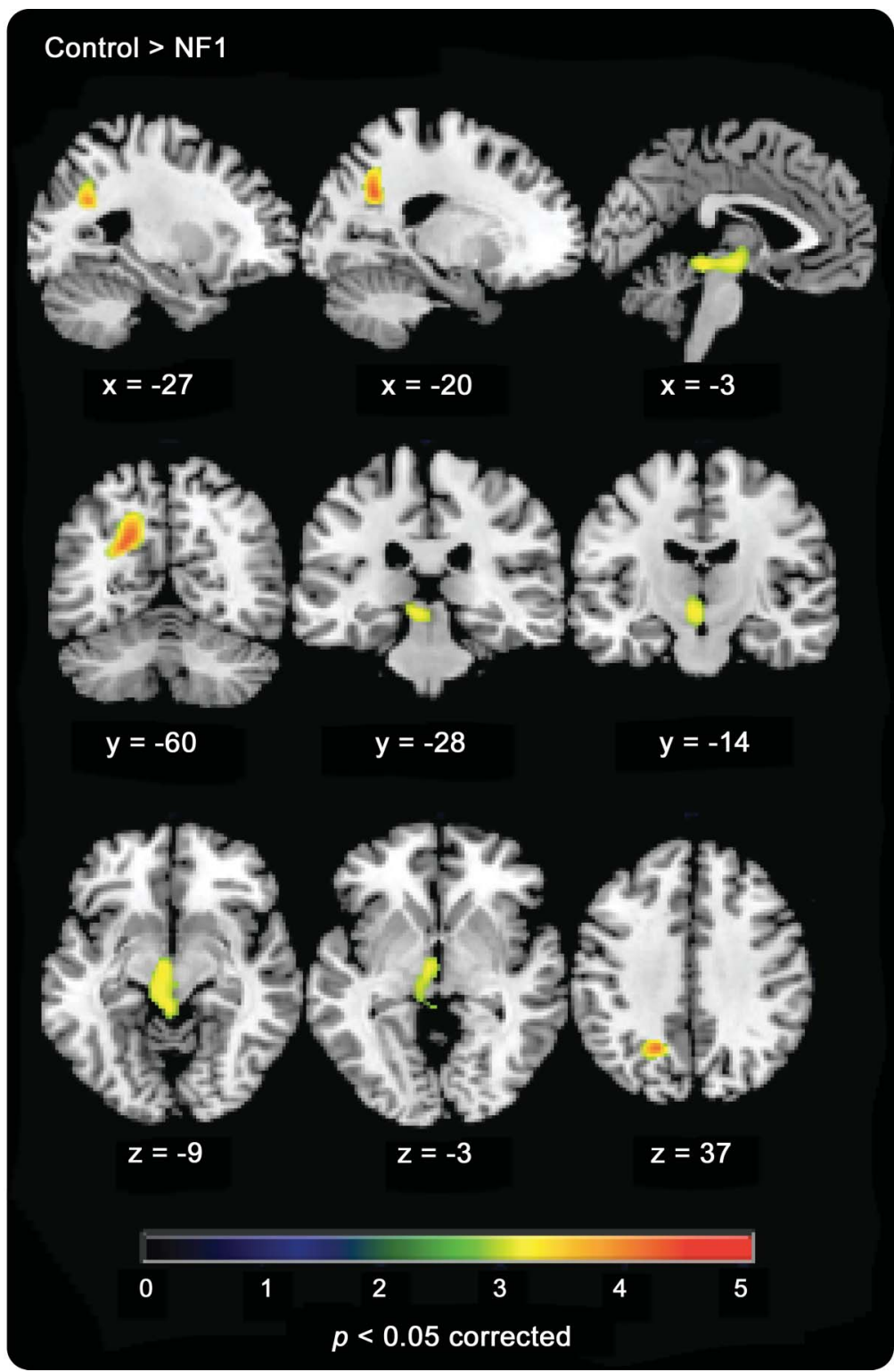

Areas showing decreased $\left[{ }^{11} \mathrm{C}\right]$-flumazenil binding in patients (contrast control $>\mathrm{NF} 1, p<$ 0.05 corrected). NF1 = neurofibromatosis type 1 .

not in the occipital cortex $(r=-0.211, p=0.469$, $\mathrm{n}=14$ ) (figure 4). In controls, we did not find any significant correlation, neither in the FEF $(r=$ $-0.342, p=0.334, \mathrm{n}=10)$ nor in the occipital cortex $(r=0.013, p=0.969, \mathrm{n}=12)$. Yet, given the correlation values in the FEF and the low sample size, it is possible that the absence of significance is attributable to a type II error.

Finally, we examined whether individual peak BOLD amplitudes elicited by the oculomotor task were related with GABA concentration or $\mathrm{GABA}_{\mathrm{A}}$ $\mathrm{BP}$. There was no significant correlation between either $\mathrm{GABA}_{\mathrm{A}} \mathrm{BP}$ or GABA+ in neither the FEF nor occipital cortex for any of the groups.
DISCUSSION We report a comprehensive study of the GABA system in patients with NF1 that investigated cortical GABA concentration using MRS and $\mathrm{GABA}_{\mathrm{A}}$ receptor density using PET imaging. Our results indicate that patients with NF1 have decreased $\mathrm{GABA}+$ levels and decreased $\mathrm{GABA}_{\mathrm{A}}$ receptors, corroborating our hypothesis that alterations in the GABA system extend beyond reduced GABA concentration.

Spectroscopy results showed that reduced GABA levels in the occipital cortex persist into adulthood, confirming our initial findings in children with $\mathrm{NF} 1,5,6$ and that this pattern is additionally observed in a frontal region centered in the FEF. Altogether, the observation of reduced GABA levels in several cortical locations (medial frontal cortex, ${ }^{5}$ occipital, and FEF) suggests a ubiquitous cortical dysfunction. Moreover, in the occipital cortex, GABA reductions were accompanied by lower glutamate and NAA + NAAG concentrations. This reduction in NAA is in agreement with earlier reports in subcortical structures $^{22,23}$ and WM. ${ }^{24}$ The fact that both glutamate and NAA are altered might be explained by the tight link between these metabolites; they are interconnected through a series of biochemical reactions, mainly the tricarboxylic acid cycle and glutamateglutamine cycle. ${ }^{25}$ It is therefore likely that reduced levels of GABA, glutamate, and NAA are linked and contributing to maintaining low levels of GABA available for neurotransmission. Furthermore, our results are in agreement with recent findings in the $\mathrm{NfI}^{+1-}$ model showing GABAergic and glutamatergic alterations. ${ }^{26}$

$\mathrm{GABA}_{\mathrm{A}}$ receptor density was also found to be reduced in patients in discrete locations: parietooccipital cortex, midbrain, and thalamus. Alterations in the parieto-occipital cortex are in agreement with functional ${ }^{27,28}$ and anatomical ${ }^{29,30}$ abnormalities reported in NF1. Likewise, thalamic metabolic ${ }^{31-33}$ and volumetric alteration $s^{30}$ have been previously reported. Both the thalamus and midbrain are important relay stations of sensory inputs to the cortex. GABAergic neurons in the thalamus are involved in the generation of synchronized activity in thalamocortical networks, ${ }^{34}$ a critical process for cognitive functions. In the midbrain, GABAergic neurons are involved in controlling the firing pattern of dopaminergic neurons. ${ }^{35}$

Of note, PET results were not hindered by concomitant abnormalities in GM. It is advisable that studies investigating differences in $\mathrm{GABA}_{\mathrm{A}}$ density using flumazenil perform GM comparisons independently, as the relationship between flumazenil BP and GM volume ${ }^{36}$ or cortical thickness ${ }^{14}$ is not homogeneous across brain regions. VBM results showed that decreased BP and decreased GM density do not 

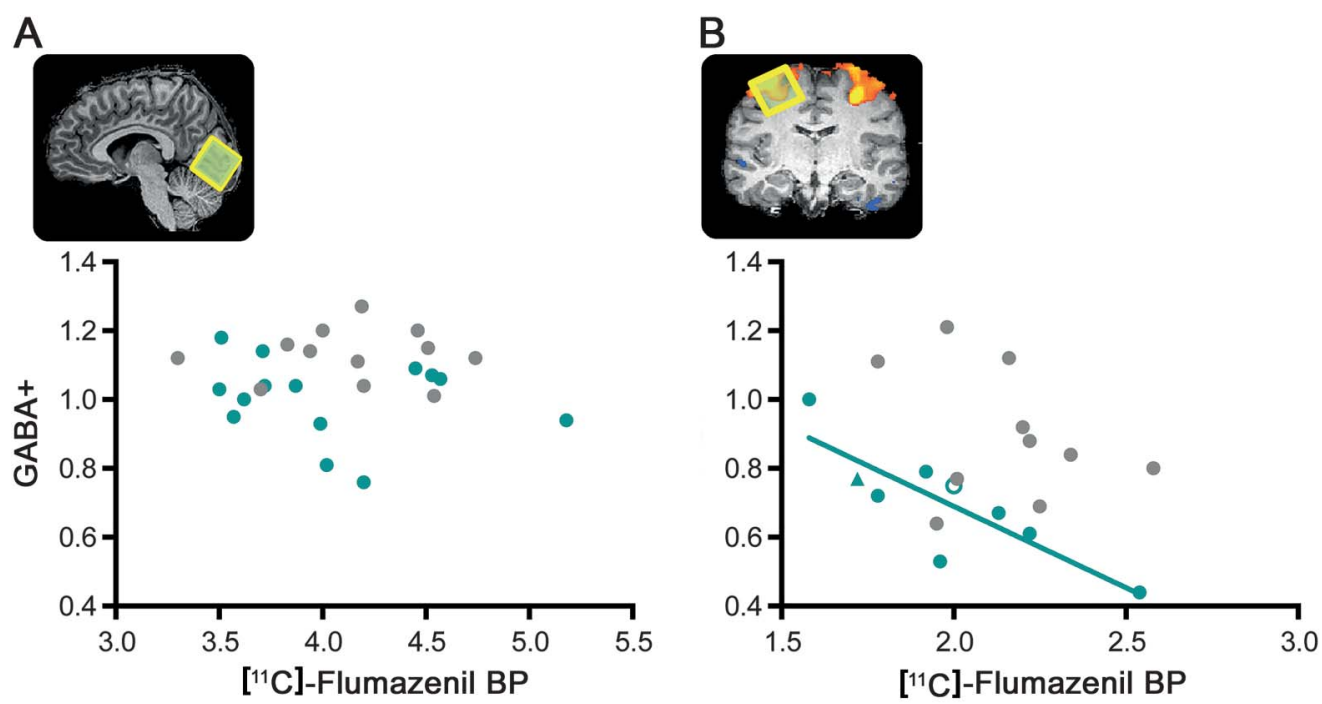

(A) Results for the occipital voxel and (B) for the FEF voxel, for patients with NF1 (green) and controls (gray). The triangle shape indicates a patient with NF1 in whom measurements were performed in the left hemisphere and the white-filled circle represents a patient in whom the FEF location was determined using anatomical landmarks. In patients with NF1, the concentration of GABA + was negatively correlated with the density of GABA type A receptors in the FEF $(r=-0.842, p=$ $0.004, \mathrm{n}=9,95 \%$ confidence interval $=-1.000$ to -0.368 calculated from 10,000 bootstrap samples). $\mathrm{BP}=$ binding potential; FEF $=$ frontal eye field; GABA $=\gamma$-aminobutyric acid; NF1 = neurofibromatosis type 1.

colocalize and are not correlated, indicating that decreased GM does not explain decreased density of $\mathrm{GABA}_{\mathrm{A}}$ receptors. Of note, we found that increased GM volume and decreased $\left[{ }^{11} \mathrm{C}\right]$-flumazenil BP in patients colocalizes, in a region including left midbrain and left thalamus. Here, GM volume is enlarged in the absence of a parallel increase in inhibitory neurons. This could either be an indication of increased populations of other neuronal types, namely, dopaminergic and glutamatergic, or that the population of inhibitory neurons preferentially expresses other types of GABA receptors. Studies with PET ligands to other receptors or postmortem studies could disentangle this hypothesis.

Our findings revealed a complex pattern of alterations in the GABA system in NF1, with both $\mathrm{GABA}+$ and $\mathrm{GABA}_{\mathrm{A}}$ reductions, yet in different locations. In addition, a negative correlation between $\mathrm{GABA}+$ and the density of $\mathrm{GABA}_{\mathrm{A}}$ receptors was observed in the FEF of patients and not in the occipital cortex. The fact that this relationship was not observed in controls is an indication that natural variation is not tightly linked for these 2 variables.

It is important to note that MRS and PET are complementary techniques measuring different components of the GABA system and it is possible that different brain regions give primacy to different regulatory mechanisms. Studies measuring GABA+ in regions showing altered $\mathrm{GABA}_{\mathrm{A}}$ binding could help disentangle the hypothesis that a reduction in both
GABA levels and $\mathrm{GABA}_{\mathrm{A}}$ receptors can occur as part of a regulatory mechanism to deal with the detrimental effects of increased GABAergic neurotransmission.

Finally, it is noteworthy that both GABA MRS and $\left[{ }^{11} \mathrm{C}\right]$-flumazenil PET are subject to limitations. Particularly important to this study is the fact that MRS is not capable of distinguishing between metabolic and synaptic pools, and $\left[{ }^{11} \mathrm{C}\right]$-flumazenil PET is not specific for the synaptic subtypes of the $G_{A B A}$ benzodiazepine receptor, as it shows affinity to both synaptic and extrasynaptic receptor subtypes. ${ }^{37}$

Overall, we now have evidence of alterations occurring at multiple levels of the GABA pathway. Studies in animal models have shown presynaptic alterations that lead to increase GABA release, ${ }^{4,26}$ while our studies in humans show that the overall concentration of GABA is reduced as well as the expression of $\mathrm{GABA}_{\mathrm{A}}$ receptors. Moreover, we showed that deficits in GABA levels do not ameliorate with age. Of note, abnormalities in the GABA system in NF1 are involved in relevant behavioral and cognitive domains including social learning, ${ }^{26}$ memory, ${ }^{28}$ and inhibitory control. ${ }^{5}$

In sum, our results point to abnormalities in the GABA system suggestive of synapthopathy, with both pre- and postsynaptic involvement.

However, given the discrete distribution of $\mathrm{GABA}_{\mathrm{A}}$ receptor abnormalities, it is difficult to support that treatments with $\mathrm{GABA}_{\mathrm{A}}$ antagonists, as suggested from the animal literature, ${ }^{4}$ would be useful to treat cognitive deficits in humans. 


\section{AUTHOR CONTRIBUTIONS}

Drafting/revising the manuscript: all authors. Study concept/design: I.R.V., I.B., J.R., A.J.A., N.F., M.C.-B. Analysis or interpretation of the data: I.R.V., I.B., J.R., M.P., M.C.-B. Acquisition of data: I.R.V., I.B. Statistical analysis: I.R.V., M.P.

\section{ACKNOWLEDGMENT}

The authors thank all participants who volunteered for this study and the Associação Portuguesa de Neurofibromatose (APNF) for their help with the study advertisement. The authors are also thankful to the staff of the Institute of Nuclear Sciences Applied to Health for successful completion of scanning procedures, in particular Mr. João Marques and Mr. Carlos Ferreira for operating the MRI scan; Dr. Marta Cró, Dr. Rodolfo Silva, Mr. Ricardo Faustino, Mr. Daniel Teixeira, Ms. Joana Rio, Ms. Cátia Neto for the acquisition of PET data; Mr. Vítor Alves for the production of $\left[{ }^{11} \mathrm{C}\right]$-flumazenil; and Ms. Sara Ribeiro for assistance with the logistics of the study.

\section{STUDY FUNDING}

This work was funded by the Portuguese Foundation for Science and Technology (FCT) (grants: COMPETE-PTDC/SAU-ORG/118380/ 2010; UID/NEU/04539/2013; COMPETE POCI-01-0145-FEDER007440) and CENTRO-07-ST24-FEDER-00205.

\section{DISCLOSURE}

I. Violante is supported by a Sir Henry Wellcome Fellowship awarded by the Wellcome Trust (103045/Z/13/Z). M. Patricio reports no disclosures relevant to the manuscript. I. Bernardino is supported by a fellowship funded by the Portuguese Foundation for Science and Technology (SFRH/BPD/101641/2014). J. Rebola, A. Abrunhosa, N. Ferreira, and M. Castelo-Branco report no disclosures relevant to the manuscript.Go to Neurology.org for full disclosures.

Received November 30, 2015. Accepted in final form May 17, 2016.

\section{REFERENCES}

1. Hyman SL, Shores A, North KN. The nature and frequency of cognitive deficits in children with neurofibromatosis type 1. Neurology 2005;65:1037-1044.

2. Jett K, Friedman JM. Clinical and genetic aspects of neurofibromatosis 1. Genet Med 2010;12:1-11.

3. Costa RM, Federov NB, Kogan JH, et al. Mechanism for the learning deficits in a mouse model of neurofibromatosis type 1. Nature 2002;415:526-530.

4. Cui Y, Costa RM, Murphy GG, et al. Neurofibromin regulation of ERK signaling modulates GABA release and learning. Cell 2008;135:549-560.

5. Ribeiro MJ, Violante IR, Bernardino I, Edden RA, Castelo-Branco M. Abnormal relationship between GABA, neurophysiology and impulsive behavior in neurofibromatosis type 1. Cortex 2015;64C:194-208.

6. Violante IR, Ribeiro MJ, Cunha G, et al. Abnormal brain activation in neurofibromatosis type 1: a link between visual processing and the default mode network. PLoS One 2012;7:e38785.

7. Miller LG, Greenblatt DJ, Barnhill JG, Summer WR, Shader RI. "GABA shift" in vivo: enhancement of benzodiazepine binding in vivo by modulation of endogenous GABA. Eur J Pharmacol 1988;148:123-130.

8. Sheikh SN, Martin DL. Elevation of brain GABA levels with vigabatrin (gamma-vinylGABA) differentially affects GAD65 and GAD67 expression in various regions of rat brain. J Neurosci Res 1998;52:736-741.

9. Neurofibromatosis: conference statement. National Institutes of Health Consensus Development Conference. Arch Neurol 1988;45:575-578.
10. Saunders JB, Aasland OG, Babor TF, de la Fuente JR, Grant M. Development of the Alcohol Use Disorders Identification Test (AUDIT): WHO Collaborative Project on Early Detection of Persons with Harmful Alcohol Consumption-II. Addiction 1993;88:791-804.

11. Cunha J. Validação da versão portuguesa dos Questionários AUDIT e Five-Shot para identificação de consumo excessivo de álcool. Lisboa: Internato Complementar de Clínica Geral da Zona Sul; 2002.

12. Wechsler D. Manual for Intelligence Scale for Adults [Portuguese adaptation]. Lisbon: Cegoc-Tea; 2008.

13. Mescher M, Merkle H, Kirsch J, Garwood M, Gruetter R. Simultaneous in vivo spectral editing and water suppression. NMR Biomed 1998;11:266-272.

14. la Fougere C, Grant S, Kostikov A, et al. Where in-vivo imaging meets cytoarchitectonics: the relationship between cortical thickness and neuronal density measured with high-resolution [18F] flumazenil-PET. Neuroimage 2011; 56:951-960.

15. Rothman DL, Behar KL, Prichard JW, Petroff OA. Homocarnosine and the measurement of neuronal $\mathrm{pH}$ in patients with epilepsy. Magn Reson Med 1997;38:924-929.

16. Edden RA, Puts NA, Harris AD, Barker PB, Evans CJ. Gannet: a batch-processing tool for the quantitative analysis of gamma-aminobutyric acid-edited MR spectroscopy spectra. J Magn Reson Imaging 2014;40:1445-1452.

17. Provencher SW. Estimation of metabolite concentrations from localized in vivo proton NMR spectra. Magn Reson Med 1993;30:672-679.

18. Gunn RN, Lammertsma AA, Hume SP, Cunningham VJ. Parametric imaging of ligand-receptor binding in PET using a simplified reference region model. Neuroimage 1997;6:279-287.

19. Lammertsma AA, Hume SP. Simplified reference tissue model for PET receptor studies. Neuroimage 1996;4: 153-158.

20. Klumpers UM, Veltman DJ, Boellaard R, et al. Comparison of plasma input and reference tissue models for analysing [(11)C]flumazenil studies. J Cereb Blood Flow Metab 2008;28:579-587.

21. Ashburner J, Friston KJ. Unified segmentation. Neuroimage 2005;26:839-851.

22. Barbier C, Chabernaud C, Barantin L, et al. Proton MR spectroscopic imaging of basal ganglia and thalamus in neurofibromatosis type 1: correlation with T2 hyperintensities. Neuroradiology 2011;53:141-148.

23. Nicita F, Di Biasi C, Sollaku S, et al. Evaluation of the basal ganglia in neurofibromatosis type 1. Childs Nerv Syst 2014;30:319-325.

24. Alkan A, Sarac K, Kutlu R, et al. Proton MR spectroscopy features of normal appearing white matter in neurofibromatosis type 1. Magn Reson Imaging 2003;21: 1049-1053.

25. Moffett JR, Ross B, Arun P, Madhavarao CN, Namboodiri AM. N-acetylaspartate in the CNS: from neurodiagnostics to neurobiology. Prog Neurobiol 2007;81: 89-131.

26. Molosh AI, Johnson PL, Spence JP, et al. Social learning and amygdala disruptions in $\mathrm{Nf1}$ mice are rescued by blocking p21-activated kinase. Nat Neurosci 2014;17: 1583-1590.

27. Clements-Stephens AM, Rimrodt SL, Gaur P, Cutting LE. Visuospatial processing in children with neurofibromatosis type 1. Neuropsychologia 2008;46:690-697. 
28. Shilyansky C, Karlsgodt KH, Cummings DM, et al. Neurofibromin regulates corticostriatal inhibitory networks during working memory performance. Proc Natl Acad Sci USA 2010;107:13141-13146.

29. Cutting LE, Cooper KL, Koth CW, et al. Megalencephaly in NF1: predominantly white matter contribution and mitigation by ADHD. Neurology 2002;59:1388-1394.

30. Violante IR, Ribeiro MJ, Silva ED, Castelo-Branco M. Gyrification, cortical and subcortical morphometry in neurofibromatosis type 1: an uneven profile of developmental abnormalities. J Neurodev Disord 2013;5:3.

31. Buchert R, von Borczyskowski D, Wilke F, et al. Reduced thalamic 18F-fluorodeoxyglucose retention in adults with neurofibromatosis type 1. Nucl Med Commun 2008;29: 17-26.

32. Kaplan AM, Chen K, Lawson MA, Wodrich DL, Bonstelle CT, Reiman EM. Positron emission tomography in children with neurofibromatosis-1. J Child Neurol 1997;12:499-506.

33. Wang PY, Kaufmann WE, Koth CW, Denckla MB, Barker PB. Thalamic involvement in neurofibromatosis type 1: evaluation with proton magnetic resonance spectroscopic imaging. Ann Neurol 2000;47:477-484.

34. Kim U, Sanchez-Vives MV, McCormick DA. Functional dynamics of GABAergic inhibition in the thalamus. Science 1997;278:130-134.

35. Tepper JM, Lee CR. GABAergic control of substantia nigra dopaminergic neurons. Prog Brain Res 2007;160:189-208.

36. Duncan NW, Gravel P, Wiebking C, Reader AJ, Northoff G. Grey matter density and GABAA binding potential show a positive linear relationship across cortical regions. Neuroscience 2013;235:226-231.

37. Mohler H, Fritschy JM, Rudolph U. A new benzodiazepine pharmacology. J Pharmacol Exp Ther 2002;300:2-8.

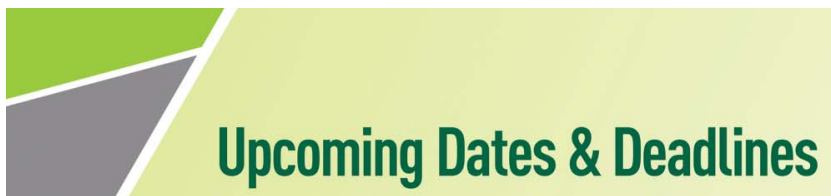

Don't miss these important dates for the 2017 AAN Annual Meeting taking place

April 22-28, 2017, in Boston, Massachusetts. Learn more at AAN.com/view/AM17.

Abstract Submission Deadline: October 24, 2016

Awards Application Deadline: October 26, 2016

Advancing Neurology. Advancing You

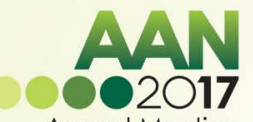

Annual Meeting

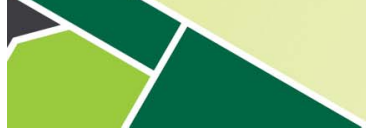

\section{Discover Altmetrics}

See real-time downloads and online activity for articles!

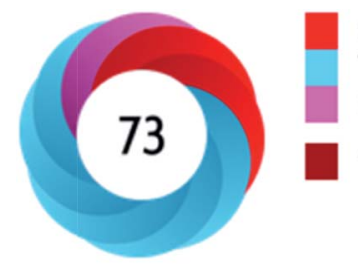

Picked up by 8 news outlets

Tweeted by 18

Mentioned in 1 Google+ posts

12 readers on Mendeley

\section{See more details}

Authors and readers alike can view real-time data on articles including downloads and online activity across multiple sources. Click on the "Article Metrics" link in the right column of an article for details. To learn more about article metrics visit http://www.neurology.org/site/misc/article_usage.xhtml. 


\section{Neurology}

\section{GABA deficiency in NF1: A multimodal [11C]-flumazenil and spectroscopy study}

Inês R. Violante, Miguel Patricio, Inês Bernardino, et al.

Neurology 2016;87;897-904 Published Online before print July 29, 2016

DOI 10.1212/WNL.0000000000003044

This information is current as of July 29, 2016

$\begin{array}{ll}\text { Updated Information \& } & \text { including high resolution figures, can be found at: } \\ \text { http://n.neurology.org/content/87/9/897.full } & \\ \text { Supplementary Material } & \text { Supplementary material can be found at: } \\ \text { http://n.neurology.org/content/suppl/2016/07/29/WNL.0000000000003 } & 044 . D C 1 \\ & \text { This article cites } 34 \text { articles, } 5 \text { of which you can access for free at: } \\ & \text { http://n.neurology.org/content/87/9/897.full\#ref-list-1 } \\ \text { References } & \text { This article has been cited by } 2 \text { HighWire-hosted articles: } \\ & \text { http://n.neurology.org/content/87/9/897.full\#\#otherarticles } \\ \text { Citations } & \text { This article, along with others on similar topics, appears in the } \\ & \text { following collection(s): } \\ \text { Developmental disorders } & \text { http://n.neurology.org/cgi/collection/developmental_disorders } \\ \text { MRS } & \text { http://n.neurology.org/cgi/collection/mrs } \\ \text { Neurofibromatosis } & \text { http://n.neurology.org/cgi/collection/neurofibromatosis } \\ \text { PET } & \text { http://n.neurology.org/cgi/collection/pet } \\ & \text { Information about reproducing this article in parts (figures,tables) or in } \\ & \text { its entirety can be found online at: } \\ & \text { http://www.neurology.org/about/about_the_journal\#permissions } \\ & \text { Information about ordering reprints can be found online: } \\ \text { http://n.neurology.org/subscribers/advertise }\end{array}$

Neurology ${ }^{\circledR}$ is the official journal of the American Academy of Neurology. Published continuously since 1951, it is now a weekly with 48 issues per year. Copyright (O 2016 American Academy of Neurology. All rights reserved. Print ISSN: 0028-3878. Online ISSN: 1526-632X.

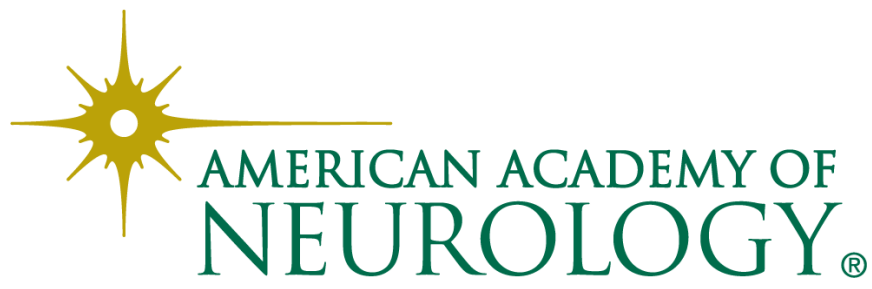

